\title{
Proximate factors influencing spawning site specificity of the puffer fish Takifugu niphobles
}

\author{
Kazunori Yamahira*
}

Amakusa Marine Biological Laboratory, Kyushu University Tomioka, Reihoku-cho, Amakusa, Kumamoto 863-25, Japan

\begin{abstract}
The puffer fish Takifugu niphobles migrates to spawn in the intertidal where it releases gametes at the water's edge at specific beaches. To examine proximate factor(s) influencing spawning site specificity of the puffer, 3 environmental characteristics [angle of inclination, bottom type (size of pebble/sand), and wave strength (relative decrease in weight of a plaster ball)] were investigated and compared between and within spawning sites. The puffer spawned at various types of beaches. Among 7 spawning sites in Japan, mean angles of inclination $\left(6.68\right.$ to $\left.11.30^{\circ}\right)$, mean pebble sizes $(4.47$ to $44.79 \mathrm{~mm}$ ), and mean wave strength (20.73 to $33.44 \%)$ differed significantly. Comparison of spawning and non-spawning areas at a single beach at Magarisaki, western Kyushu, showed that mean angle of inclination was significantly larger in spawning areas $\left(8.84^{\circ}\right)$ than in non-spawning areas $\left(5.33^{\circ}\right)$, but mean size of pebbles $(30.04$ and $32.51 \mathrm{~mm})$ and mean wave strength $(22.58$ and $21.62 \%$ in the spawning and non-spawning areas, respectively) were not different. A discriminant analysis and stepwise multiple regression analysis indicated that only the angle of inclination significantly contributed (1) to discrimination between spawning and non-spawning areas, and (2) to variation in the frequency of spawning along the Magarisakı beach. The range of mean angles in the spawning areas of Magarisaki $\left(5.88\right.$ to $10.77^{\circ}$ ) included most of the mean angles of the 7 spawning beaches in Japan. These results suggest that the puffer prefers a range of angles as the criterion used when selecting spawning sites. The preference for particular inclination angles appears to be for the benefit of adult spawners rather than the benefit of developing embryos or larvae: moderately inclined beaches are likely to provide an environment where adult puffers can easily gather, strand, and spawn.
\end{abstract}

KEY WORDS Proximate and ultimate factor - Intertidal spawning · Site specificity · Environmental features Inclination. Takifugu niphobles

\section{INTRODUCTION}

Some marine fishes migrate for spawning and release their gametes at specific spawning sites (e.g. Walker 1959, Colin \& Clavijo 1978, Johannes 1978, Middaugh et al. 1981, Warner 1988). Several studies have discussed the adaptive significance of the preference for specific spawning sites. In the case of reefinhabiting pelagic spawners, it is assumed that this pattern of spawning results from the same selective pressures that cause the spawning migration (i.e. situating the eggs and larvae in the optimal location for transport offshore and subsequent return to the reef)

\footnotetext{
·E-mail:kayamsca@mbox.nc.kyushu-u.ac.jp
}

(Johannes 1978, Lobel 1978, Lobel \& Robinson 1983 , Thresher 1984, Colin \& Clavijo 1988). Such fishes ought to be able to perceive some kinds of environmental features of their specific spawning sites which are distinct from those of other sites, and which would be expected to be advantageous for reproductive success through the benefit of developing embryos or larvae and/or the benefit of adult spawners. Thus, to verify the hypotheses on the adaptive significance of spawning site specificity, it would be helpful to detect proximate factors which determine the site-specific spawning, i.e. how the fishes select their specific spawning sites, or what they use as a criterion for spawning site specificity.

The puffer fish Takifugu niphobles is an intertidal spawner and produces demersal eggs. They usually inhabit shallow sandy areas (Katayama \& Fujita 1966. 
Miyamoto 1982, Yamahira et al. 1996), but have been reported to release their gametes en masse at the water's edge (e.g. Uno 1955, Honma et al. 1980, Yamahira 1994). Spawning sites of the fish are restricted to specific beaches in Japan. Several proximate factors influencing spawning site specificity have been discussed in earlier works. Katayama \& Fujita (1967) hypothesized that spawning sites of the puffer face south. Moreover, Tsutsumi (1978) suggested that the puffer selects beaches where underground water is oozing out. However, these hypotheses have not been verified on various beaches of Japan, and thus a theory for spawning site specificity needs to be established. Such a theory may be helpful not only in suggesting the ultimate explanation for site-specific spawning of marine fishes, but also for conserving their spawning sites in order to help conserve the species themselves.

To examine the proximate factor(s) for spawning site specificity of the puffer, the relationship between spawning of the puffer and environmental features of spawning sites was analyzed in this study. The 2 objectives of this study were (1) to detect which feature(s) is/are similar between spawning sites and (2) to detect which feature(s) is/are different between a spawning site and non-spawning site within a single, continuous beach. Although the direction of the beach and the presence of springs in the beach were noted, this study mainly focused on 3 environmental features that are thought to affect spawning behavior and the fate of released eggs (Katayama et al. 1964, Nozaki et al. 1976): (1) angle of inclination, (2) bottom type (size of pebble/sand), and (3) wave strength (relative decrease in the weight of a plaster ball). This report describes the characteristics of a beach that are favorable for spawning of the puffer, and then discusses the functional explanation (the ultimate factor) for the spawning site specificity.

\section{MATERIALS AND METHODS}

Fish. Generally, spawning of the puffer occurs only during the rising tidal phases at dusk for several days of spring tides, although the timing and days of spawning vary slightly among spawning sites in Japan (see Uno 1955, Katayama et al. 1964, Nozaki et al. 1976, Tsutsumi 1978, Suzuka \& Isogai 1979. Honma et al. 1980, Dotsu et al. 1990. Yamahira 1994). Before spawning, hundreds to thousands of mature fish slowly enter the beach area during the rising tide, and swim en masse along the beach for 1 or $2 \mathrm{~h}$. Soon they strand themselves on the beach using an incoming wave and flop back into the wash of the next wave. After repeating this behavior for about $10 \mathrm{~min}$, they suddenly begin to spawn, splashing at the water's edge and making the seawater around them white with their milt. Each spawning is conducted by a group of 10 to 60 individuals that includes only 1 female (Nozaki et al. 1978), and is completed within about $5 \mathrm{~s}$. Such group spawning is repeated several to several hundred times within a spawning day. A day's spawning lasts for $\leq$ about $2 \mathrm{~h}$ (Yamahira 1994). Since the tide level is rising during the period of a day's spawning, the zone where spawning occurs also rises.

Comparison among spawning sites. At each of 7 puffer spawning sites so far identified in Japan (Fig. 1). I observed puffer spawning for a $4 \mathrm{~d}$ period during May-July 1995. The observations were made from the shore, and did not affect spawning behavior at all. The following features were also recorded at each site: (1) the angle of inclination, (2) size of bottom substrate, and (3) wave strength present at each beach during the time of observation.

On each spawning day, the exact area in which spawning occurred was determined; tide levels at the start and end (vertical width) and distance along the beach where each day's spawning occurred were recorded by marking directly on the beach using stainless steel piles. On the day following each spawning day, the height and distance between the start and end tide levels were measured, and the angle of inclination $\left(a^{\circ}\right)$ was calculated using a trigonometric function (Fig. 2a). Ten such angles were calculated on each day, at locations that divided the spawning area into 10 equal parts. A total of 40 angles were measured at each site during the time of observation.

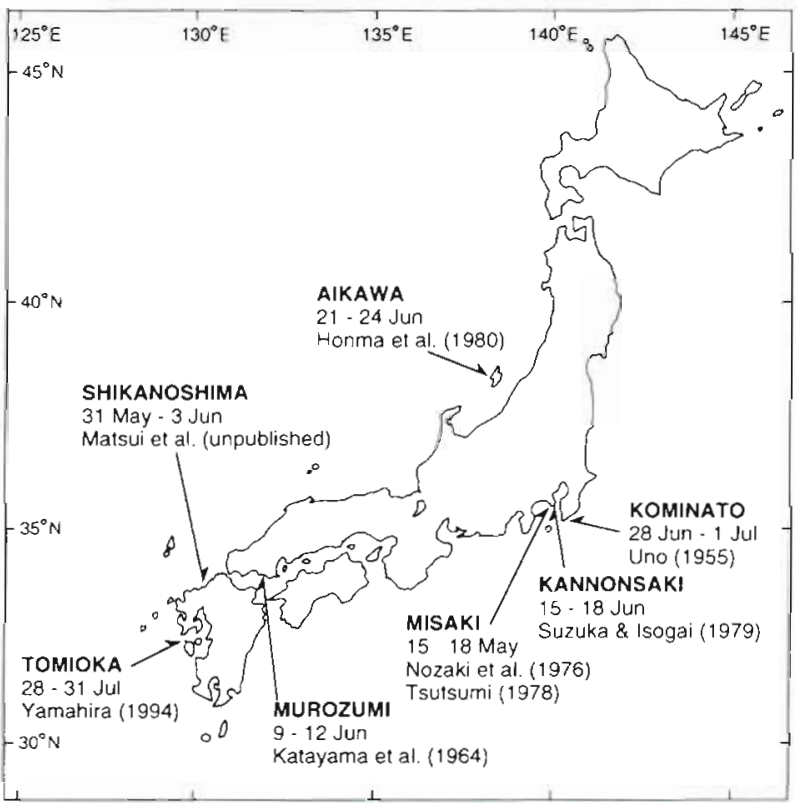

Fig. 1. Map showing distribution of the 7 puffer spawning sites in Japan examined in this study. Date each site was studied and references are listed under the name of each site 
(a)

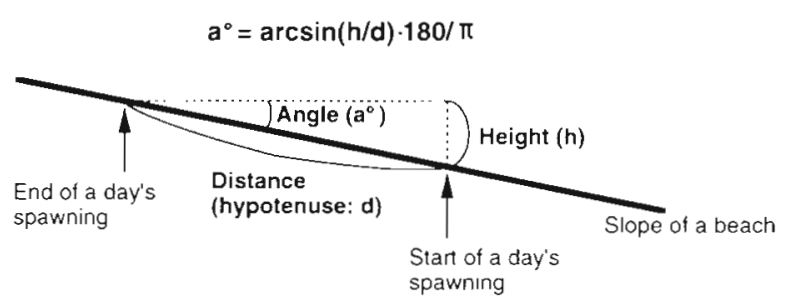

(b)

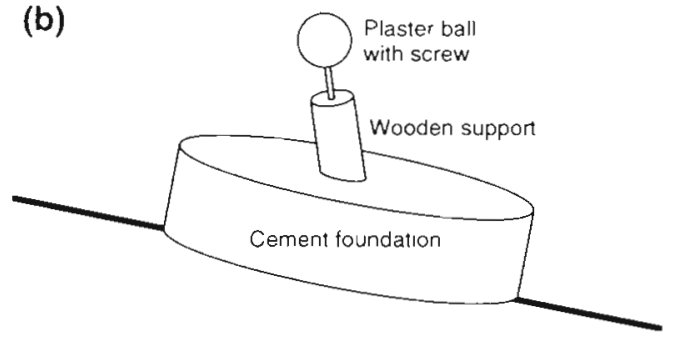

Fig. 2. (a) Schematic diagram of the profile of a spawning beach. The angle of inclination was calculated from the height and hypotenuse of spawning zone using an arcsine transformation. (b) Plaster ball to estimate wave strength. Each ball was screwed into a wooden support that was attached to a cement foundation

At the daytime low tide on each day when spawning was expected to occur (and just occurred), 5 plaster balls (37 $\mathrm{mm}$ in diameter) of known dry weight (ca $35 \mathrm{~g}$ ) were fixed to cement foundations and then placed just under the water surface (subtidal zone) where they would be eroded by water motion (Fig. 2b). The balls were collected after $24 \mathrm{~h}$, dried $\left(60^{\circ} \mathrm{C}, 72 \mathrm{~h}\right)$ and weighed. A total of 15 to 20 plaster balls were set during the time of observation. Komatsu \& Kawai (1992) revealed that the temporal rate of decrease in the $1 / 2$ power of weight of plaster balls was proportional to the speed of steady flow in an experimental tank. On the basis of this relation, they proposed the method in the field for estimating the time-averaged intensity of water motion by measuring weight loss of plaster balls. In the present study, percent decrease in weight of plaster balls was regarded as a measure of the wave strength.

A $10 \times 10 \mathrm{~cm}$ quadrat was set at the center of the spawning area at the 2 sandy beaches (Misaki and Kannonsaki; Fig. 1) and a $50 \times$ $50 \mathrm{~cm}$ quadrat was set at the center of the spawning area at the other 5 pebble beaches Since each beach was very homogenous, the quadrat is fully representative of the entire beach. The longest diameter of each of 500 pebbles or sand grains within the quadrat was measured during the daytime low tide on the day after the last spawning day.

Kruskal-Wallis tests were used to examine similarity or difference in each of the environmental parameters among the 7 spawning sites, and followed by Scheffé methods for multiple comparisons.

Comparison among spawning and non-spawning sites. Magarisaki sand spit, located at northern Amakusa Shimoshima Island, western Kyushu, Japan $\left(32^{\circ} 31^{\prime} \mathrm{N}, 130^{\circ} 2^{\prime} \mathrm{E}\right)$, is a long coastline composed of pebbles. At this location, spawning of the puffer is restricted to the tip of the sand spit (Fig, 3). Twenty $10 \mathrm{~m}$ areas were established along the coastline on and around the spawning site, including some areas at both ends where spawning never occurred. Spawning was observed for $4 \mathrm{~d}$ (12 to $15 \mathrm{July}$ ) in 1995. At areas where spawning occurred, the number of group spawnings and tide levels at the start and end of the day's spawning within each area were recorded on each spawning day. At areas where spawning did not occur, tide levels at the times when the day's spawning started and ended throughout the area were recorded. On the day after each spawning day, beach angles were measured, as before, every $2 \mathrm{~m}$ within each area, such that 5 measurements were made within each of the 20 areas. A plaster ball was positioned in the middle of each of the $10 \mathrm{~m}$ areas on each spawning day to measure wave strength as described above. A total of 20 angles and 4 measures of wave strength were calculated at each area during the time of observation. Finally, 500 pebbles were randomly selected from a

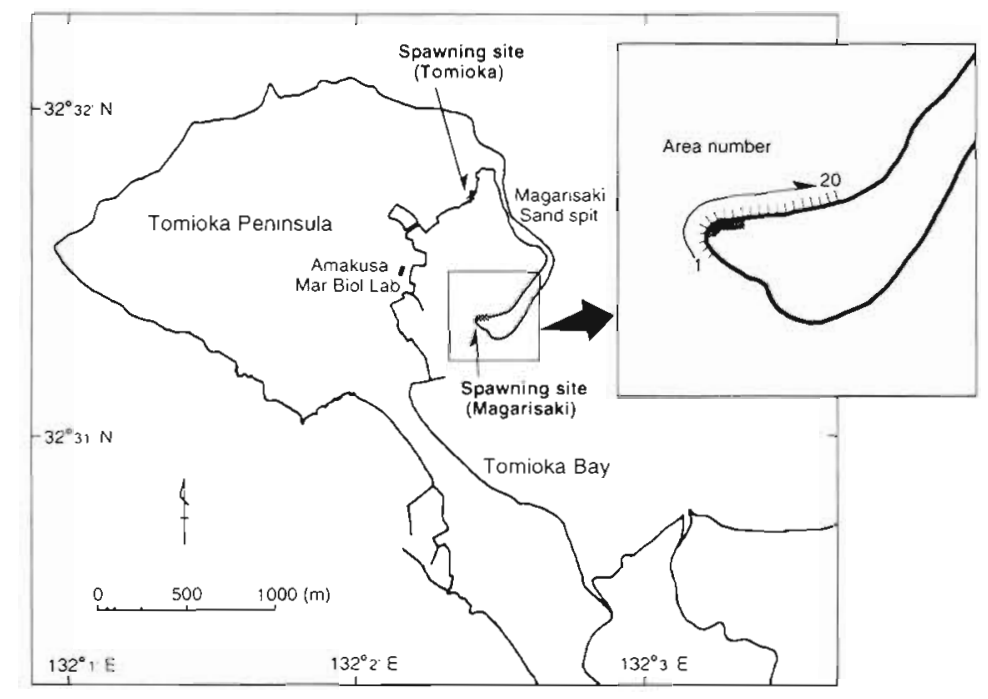

Fig. 3. Study site at Magarisaki sand spit. Twenty $10 \mathrm{~m}$ wide areas were established along the coastline on and around the spawning site at the tip of Magarisaki. The shaded part indicates the spawning areas 
$50 \times 50 \mathrm{~cm}$ quadrat at the center of each area, and the size (longest diameter) was measured.

In my analysis, I first classified the areas into 2 groups: those in which spawning occurred at least once (spawning areas) and those in which it never occurred (non-spawning areas). To examine for differences in (1) mean angle of inclination, (2) mean size of pebbles, and (3) mean wave strength (relative reduction in plaster balls) between the groups, nested ANOVAs were performed on the factors area group (spawning/non-spawning areas) and $10 \mathrm{~m}$ area nested within the area group.

Second, to examine environmental features distinguishing between the spawning and non-spawning areas, a linear discriminant analysis was used. The mean angle of inclination $\left(X_{1}\right)$, mean size of pebbles $\left(X_{2}\right)$, and mean wave strength $\left(X_{3}\right)$ at each area were regarded as variables, and discriminant functions for each of the spawning and non-spawning areas were evaluated. Whether each variable significantly contributed to the discrimination was tested by evaluating the $F$-value for each variable (partial $F$ ). Each area was also classified by discriminant scores calculated from the discriminant functions.

Last, to estimate the contribution of these 3 variables $\left(X_{1}\right.$ to $\left.X_{3}\right)$ to the number of spawnings in each area, a stepwise multiple regression analysis was used. The number of group spawnings over the 4 spawning days was summed up within each area and regarded as a dependent variable $(Y)$. Since the maximum $Y$ may lie within the range of the independent variables, that is, since $Y$ may be expressed by a quadratic function of $X$, squares of the mean angle of inclination $\left(X_{4}\right)$, mean pebble size $\left(X_{5}\right)$, and mean wave strength $\left(X_{6}\right)$ were also regarded as independent variables. The decisions on whether to add or remove a variable were based on the $F$-value (partial $F$ ). All variables with a statistically significant ( $5 \%$ level) regression coefficient were identified.

\section{RESULTS}

\section{Comparison among spawning sites}

Various types of beaches were used by Takifugu niphobles as spawning sites in Japan (Table 1).

The puffer spawned on beaches having a rather gentle slope Mean angle of inclination at the 7 spawning sites ranged from 6.68 (Kannonsaki) to $11.30^{\circ}$ (Shikanoshima). Mean angle of inclination differed significantly among spawning beaches (Kruskal-Wallis test, $d f=6, p<0.0001$ ). According to the mean order of the angles and the multiple comparisons between the means, the spawning sites were classified into 3 groups. Shikanoshima, Kominato, Aikawa, and Tomioka were classified into higher orders. In contrast, Kannonsaki, Murozumi, and Misaki were grouped into the lowest, and differed significantly from the higher groups.

Mean size of pebbles composing each beach differed significantly between spawning sites (Kruskal-Wallis test, $\mathrm{df}=6, p<0.0001$ ). In Kannonsaki and Misaki, the puffer spawned on sandy beaches (mean pebble size = 4.47 and $5.53 \mathrm{~mm}$, respectively). In contrast, the puffer also spawned on beaches with larger pebbles in Shikanoshima, Tomioka, and Aikawa (44.79, 39.32, and $39.14 \mathrm{~mm}$, respectively). Multiple comparisons indicated that the beaches tended to differ considerably from each other: only 2 pairs (Tomioka-Aikawa and Misaki-Kannonsaki) had no significant difference. The beaches with larger pebbles tended to be classified into higher orders in the mean angle of inclination, but the rank correlation was not significant (Kendall's

Table 1 Angle of inclination, size of pebbles/sand, and percent decrease in weight of plaster balls (i.e. wave strength) at the 7 puffer spawning sites in Japan (n: number of samples). Results of multiple comparisons using Scheffé method are showed ${ }_{i}$ lines under abbreviation names of spawning sites indicate that no significant difference in the mean order of each parameter was detected between any pairs of spawning sites. Direction of each beach and presence of springs are also listed. $\mathrm{Y}$ (yes) and $\mathrm{N}$ (no) indicate whether or not presence of springs has been previously reported in the literature

\begin{tabular}{|c|c|c|c|c|c|}
\hline Spawning site & $\begin{array}{c}\text { Inclination angle }\left({ }^{\circ}\right) \\
M \pm S D(n)\end{array}$ & $\begin{array}{l}\text { Pebble size }(\mathrm{mm}) \\
M \pm S D(\mathrm{n})\end{array}$ & $\begin{array}{l}\text { Decrease in plaster }(\%) \\
\qquad M \pm S D(n)\end{array}$ & $\begin{array}{l}\text { Direction of } \\
\text { beach }\end{array}$ & $\begin{array}{l}\text { Presence } \\
\text { of springs }\end{array}$ \\
\hline Misaki (Ms) & $7.25 \pm 1.26(40)$ & $5.53 \pm 2.14(500)$ & $29.10 \pm 4.66(20)$ & West & $\mathrm{Y}$ \\
\hline Shikanoshima (S) & $11.30 \pm 2.87(40)$ & $44.79 \pm 22.92(500)$ & $31.47 \pm 2.88(15)$ & East & $N$ \\
\hline Murozumi (Mr) & $7.25 \pm 1.66(40)$ & $19.58 \pm 16.13(500)$ & $32.53 \pm 2.05(15)$ & South & $\mathrm{N}$ \\
\hline Kannonsaki (Kn) & $6.68 \pm 0.89(40)$ & $4.47 \pm 2.56(500)$ & $32.83 \pm 1.83(15)$ & South & $\mathrm{N}$ \\
\hline Aikawa $(\mathrm{A})$ & $10.11 \pm 2.97(40)$ & $39.14 \pm 27.95(500)$ & $33.44 \pm 6.92(19)$ & West & $\mathrm{Y}$ \\
\hline Kominato $(\mathrm{Km})$ & $10.65 \pm 1.81(40)$ & $25.17 \pm 27.01(500)$ & $29.21 \pm 2.41(15)$ & South & $\mathrm{N}$ \\
\hline Tomioka (T) & $9.27 \pm 2.52(40)$ & $39.32 \pm 27.23(500)$ & $20.73 \pm 0.85(20)$ & East & $N$ \\
\hline \multicolumn{2}{|c|}{ Multiple comparisons S Km A T Ms Mr Kn } & $\mathrm{S} I \mathrm{~A} \mathrm{Km} M \mathrm{Mr} \mathrm{Mn}$ & $\mathrm{AKnMrSKmMs} T$ & & \\
\hline
\end{tabular}


coefficient of rank correlation, $\tau=0.62, \mathrm{n}=7, \mathrm{p}=$ 0.0509).

Wave strength was more similar among spawning sites than the other 2 environmental features of the beaches. At each of the spawning sites except Tomioka, the mean reduction in weight of the plaster balls was about $30 \%$. However, wave strength was significantly different between sites (Kruskal-Wallis test, $\mathrm{df}=6, \mathrm{p}<0.0001$ ). Only the mean reduction in Tomioka was significantly smaller than the other 6 spawning sites, all of which had no significant difference from each other.

Beaches faced in different directions, and some had springs while others did not (Table 1).

\section{Comparison among spawning and non-spawning sites}

Spawning of the puffer was restricted to the tip of Magarisaki sand spit. The spawning area was a $60 \mathrm{~m}$ section along the shoreline from Area 4 to Area 9 (Fig. 4a; see also Fig. 3). The area where spawning occurred most frequently was Area 8 (total number of group spawnings $=179$ ). On both sides of the spawning area (Areas 1 to 3 and 10 to 20), spawning was not observed.

The areas were classified into 2 groups: (1) spawning areas (Areas 4 to 9) and (2) non-spawning areas (Areas 1 to 3 and 10 to 20). Mean angle of inclination, mean size of pebbles, and mean wave strength were significantly different among the twenty $10 \mathrm{~m}$ areas nested within the area group (Table 2). Inclination angle tended to be larger at the tip of the spit (Fig. $4 \mathrm{~b}$ ), and the most inclined area was Area 5 (mean angle $\pm \mathrm{SD}=$ $10.77 \pm 1.30^{\circ}, \mathrm{n}=20$ ). Mean pebble size in the 20 areas ranged from 20 to $45 \mathrm{~mm}$ (Fig. 4c). However, there was no relation between the size of pebbles and their location along the beach. Wave strength tended to be greater in the areas nearer to the open sea (Fig. 4d), and the most exposed area was Area 3 (mean decrease in plaster $\pm \mathrm{SD}=28.15 \pm 2.82 \%, \mathrm{n}=4$ )

Mean angle of inclination was significantly different between the area groups (Table 2a): it was significantly larger in the spawning areas $\left(8.84 \pm 1.98^{\circ}, \mathrm{n}=\right.$ 120) than in the non-spawning areas $\left(5.33 \pm 0.91^{\circ}, \mathrm{n}=\right.$ 280). Mean size of pebbles was not significantly different between the spawning areas $(30.04 \pm 16.09 \mathrm{~mm}$, $\mathrm{n}=3000)$ and the non-spawning areas (32.51 \pm $19.49 \mathrm{~mm}, \mathrm{n}=7000$ ) (Table 2b). Mean wave strength also did not differ between the spawning areas $(22.58$ $\pm 1.90 \%, \mathrm{n}=24)$ and the non-spawning areas (21.62 \pm $3.27 \%, \mathrm{n}=56$ ) (Table 2c).

Table 3 shows discriminant functions for the spawning and non-spawning areas. As a whole, the discrimi-

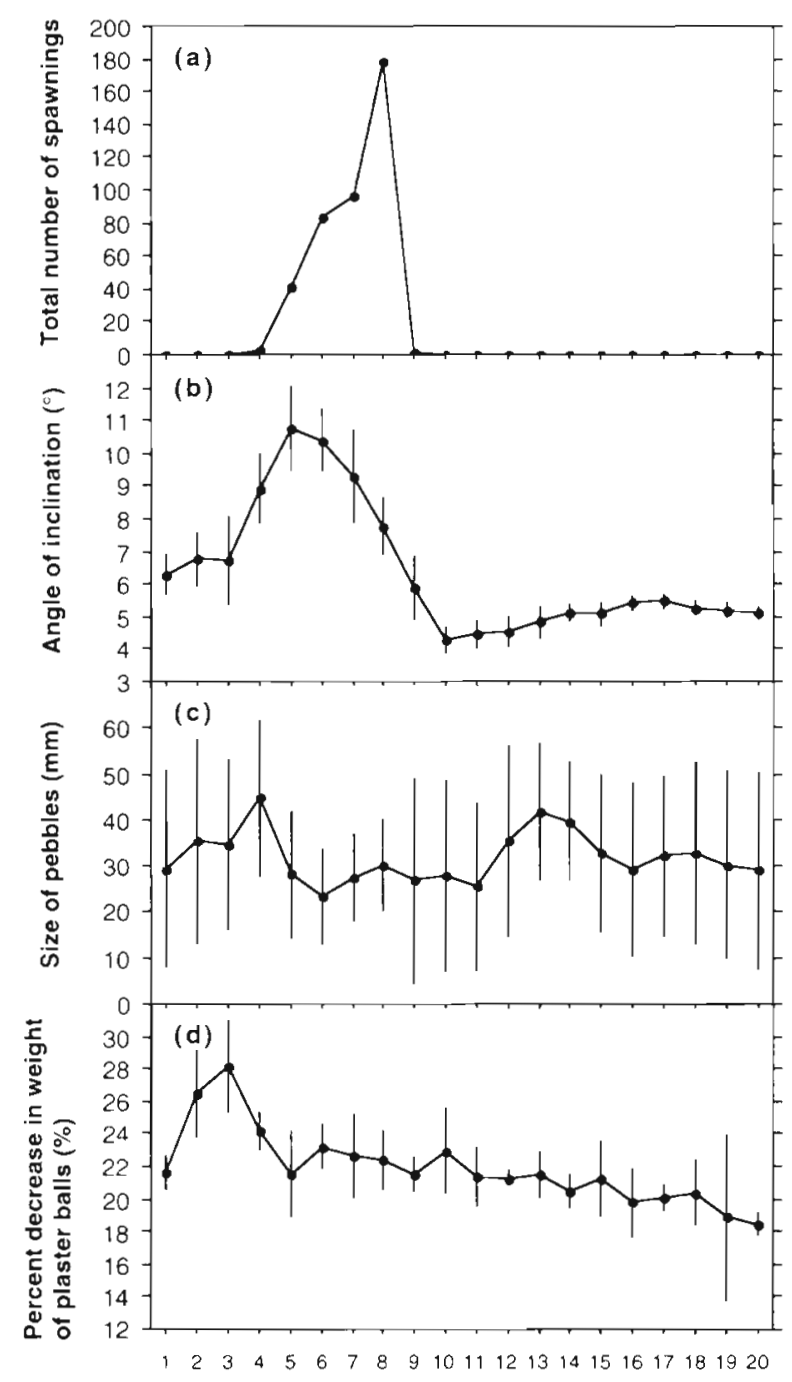

Area number

Fig. 4. Takifugu niphobles. Characteristics of puffer spawning sites at Magarisaki sand spit. (a) Frequency of spawning (total number of group spawnings): (b) mean angle of inclination; (c) mean size of pebbles; (d) mean wave strength (percent decrease in weight of plaster balls). Vertical bars show $\pm 1 \mathrm{SD}$

nation was significant [Wilks' $\Lambda=0.30, F=12.40>F^{3}{ }_{16}$ $(0.01)=5.18]$. The mean angle of inclination $\left(X_{1}\right)$ contributed most to the discrimination between the spawning and non-spawning areas, and the contribution was significant [partial $F=31.76>F_{15}^{1}(0.01)=$ 8.68). However, the mean size of pebbles $\left(X_{2}\right)$ (partial $F$ $=0.55$ ) and wave strength as measured by the relative decrease in the plaster balls $\left(X_{3}\right)$ (partial $F=0.11$ ) did not contribute significantly to the discrimination. Using the discrimination function, 5 out of the 6 spawning areas $(83.33 \%)$ were correctly classified as spawning areas (Table 4): only Area 9 was misclassified. At Area 9, however, only 2 spawnings were observed 
during the period of observation. In contrast, nonspawning areas (14 cases) showed perfect discrimination.

The total number of spawnings in each area was determined only by the mean angle of inclination $\left(X_{1}\right)$ (Table 5). The mean angle could account for $34.92 \%$ (square of standard regression coefficient) of the variance in the total number of spawnings. Since the sign of the regression coefficient was positive, the puffer tended to spawn at more inclined areas at Magarisaki spit. The mean size of pebbles $\left(X_{2}\right)$ and wave strength $\left(X_{3}\right)$ did not contribute significantly to the variance in the total number of spawnings, nor did the terms of the second degree $\left(X_{4}\right.$ to $\left.X_{6}\right)$.

Table 2. Summary of nested ANOVAs of (a) angle of inclination, (b) size of pebbles, and (c) percent decrease in plaster balls (i.e. wave strength) on the factors area group (spawning/non-spawning areas) and $10 \mathrm{~m}$ area within the area group

\begin{tabular}{|lrrrrr}
\hline Source & df & SS & MS & $F$ & \multicolumn{1}{c|}{ p } \\
\hline (a) Angle of inclination & & & & \\
Area group & 1 & 570.53 & 570.53 & 21.52 & 0.0002 \\
lo m area & 18 & 477.31 & 26.52 & 14.72 & $<0.0001$ \\
Residual & 380 & 684.33 & 1.80 & & \\
(b) Size of pebbles & & & & \\
Area group & 1 & 12731.63 & 12731.63 & 0.83 & 0.3748 \\
10 m area & 18 & 276629.20 & 15368.29 & 48.56 & $<0.0001$ \\
Residual & 9980 & 3158659.84 & 316.50 & & \\
(c) Decrease in plaster & & & & \\
Area group & 1 & 15.65 & 15.65 & 0.70 & 0.4126 \\
10 m area & 18 & 400.48 & 22.25 & 4.93 & $<0.0001$ \\
Residual & 60 & 270.71 & 4.51 & & \\
\hline
\end{tabular}

Table 3. Coefficients of discriminant functions and partial $F$-values for environmental characters. Discriminant score for the spawning areas $\left(u_{1}\right)$ and nonspawning areas $\left(u_{2}\right)$ is expressed as: $u_{1}=4.33 X_{1}+0.64 X_{2}+2.87 X_{3}-61.12$; $u_{2}=1.44 X_{1}+0.70 X_{2}+3.20 X_{3}-49.74$

\begin{tabular}{|lccr|}
\hline Variables & $\begin{array}{c}\text { Spawning } \\
\text { areas }\end{array}$ & $\begin{array}{c}\text { Non-spawning } \\
\text { areas }\end{array}$ & Partial $F$ \\
\hline Inclination angle $\left(X_{1}\right)$ & 4.33 & 1.44 & 31.76 \\
Pebble size $\left(X_{2}\right)$ & 0.64 & 0.70 & 0.11 \\
Decrease in plaster $\left(X_{3}\right)$ & 2.87 & 3.20 & 0.55 \\
Constant & -61.12 & -49.74 & \\
\hline
\end{tabular}

\section{DISCUSSION AND CONCLUSION}

Results from this study suggest that the angle of inclination of a beach is an important proximate factor influencing spawning site specificity of Takifugu niphobles. For example, the stepwise multiple regression analysis indicated that only the angle of inclination could explain the frequency of spawnings along a coast. In addition, the discriminant analysis indicated that only the angle of inclination significantly contributed to discrimination between spawning and nonspawning areas within the beach. At Magarisaki, the spawning areas were significantly more inclined than were the non-spawning areas.

Although each of the spawning sites in Japan had a different mean angle of inclination, this should be interpreted as an indication that the puffer prefers a range of angles rather than different angles at different sites. Mean angle of inclination at the 7 spawning beaches in Japan ranged from 6.68 to $11.30^{\circ}$. On the other hand, at Magarisaki spit, the mean angle of inclination in the spawning areas ranged from 5.88 to $10.77^{\circ}$. The overall range noted was almost entirely included within the latter: 6 of the 7 spawning beaches had their mean angle within this range, suggesting that there is a preferred range of angles.

Substrate type present at a beach did not appear to influence puffer spawning. Various bottom types, ranging from sand (Misaki and Kannonsaki) to boulders (Shikanoshima, Aikawa, and Tomioka), were used. At Magarisaki, pebble size did not differ between the spawning and nonspawning areas. In addition, the multivariate analyses indicated that there was no relation between the size of pebbles and puffer spawning. At some spawning sites, spawning occurs on rocky beaches, and gametes are re-

Table 4. Result of discrimination between the spawning areas (SPA) and non-spawning areas (NSPA) using the discriminant functions

\begin{tabular}{|lcccc|}
\hline Group & No. of total cases & No. of correct cases & Percent correct & \multicolumn{2}{c|}{$\begin{array}{c}\text { No. of cases classified } \\
\text { SPA. }\end{array}$} \\
\hline Spawning areas (SPA) & & & 83.33 & 5 \\
Non-spawning areas (NSPA) & 14 & 14 & 100.00 & 0 \\
\hline
\end{tabular}


Table 5. (a) Stepwise multiple regression analysis to estimate contributions of the angle of inclination, size of pebbles, and percent decrease in weight of plaster balls (i.e. wave strength) to the total number of group spawnings in each area. NS indicates no statistically significant association between variables. (b) ANOVA summary of the regression

(a) Stepwise multiple regression (adjusted $\mathrm{R}^{2}=0.31$ )

\begin{tabular}{|c|c|c|c|c|c|}
\hline & \multicolumn{2}{|c|}{ Regression coefficient } & Standard error & \multicolumn{2}{|c|}{ Standard regression coefficient } \\
\hline Inclination angle $\left(X_{1}\right)$ & & 13.88 & 4.47 & & \\
\hline Pebble size $\left(X_{2}\right)$ & & NS & & & \\
\hline Decrease in plaster $\left(X_{3}\right)$ & & NS & & & \\
\hline Square of inclination angle $\left(X_{4}\right)$ & & NS & & & \\
\hline Square of pebble size $\left(X_{5}\right)$ & & NS & & & \\
\hline Square of decrease in plaster $\left(X_{6}\right)$ & & NS & & & \\
\hline Intercept & & -68.30 & 29.79 & & \\
\hline \multicolumn{6}{|l|}{ (b) ANOVA summary } \\
\hline Source & $\mathrm{df}$ & SS & MS & $F$ & $\mathrm{p}$ \\
\hline Regression & 1 & 14596.90 & 14596.90 & 9.66 & 0.006 \\
\hline Residual & 18 & 27208.85 & 1511.60 & & \\
\hline
\end{tabular}

leased on the surface of rocky outcroppings, where there are no particles of sand or pebbles (Katayama \& Fujita 1967, Nozaki et al. 1976).

Also, relative decrease in plaster balls did not differ between the spawning and non-spawning areas in Magarisaki, and the multivariate analysis showed no relation between the decrease in plaster and puffer spawning. These results suggest that spawning site specificity was not affected by wave strength. However, judging from the fact that spawning was suppressed or completely halted on stormy days, there seems to be an upper limit to wave strength tolerance for spawning to occur. Therefore, in this context, wave strength does have an effect on spawning. At Areas 1 to 3 in Magarisaki, which have suitable angles of inclination, spawning was never observed. This is probably because the areas are more exposed and not suitable for spawning.

The ultimate factor for the preference of inclination angle is considered to be related to spawning behavior of the adult puffers: moderately inclined beaches are likely to provide an environment where adult puffers can easily gather, strand, and spawn. At beaches of extremely small angles, it would be physically or morphologically difficult for adult puffers to enter and spawn at the water's edge because of the too shallow water column (Fig. 5). It is believed that spawning did not occur in Areas 10 to 20 at Magarisaki because the beach angles were too low. On the other hand, at extremely inclined beaches, it would be difficult for an adult to strand and stay at the water's edge. Moreover, few adults can gather simultaneously into a spawning group on extremely inclined beaches, because the available area where the water column is moderately shallow and adults can strand would be too small. In order to be washed up onto the beach, adult puffers have to gather along the narrow line of the water's edge, and if the width of this line is small, there will be a reduction in the number of fish in a spawning group. Thus, moderately inclined beaches should be ultimately preferred by adults. In addition to moderate angles of spawning sites, wave strength also seems to be related to the ease of spawning at the water's edge. Intense waves are likely to suppress the gathering and stranding behaviors. In the case of the puffer, although it might be unlikely that the angle of inclination is the only criterion for selecting a spawning site, it is likely that the fish spawn at beaches where, at least, they can easily gather. In fact, mature adults swim en masse along the coastline near the spawning site before spawning, suggesting that they are testing suitable sites for spawning.

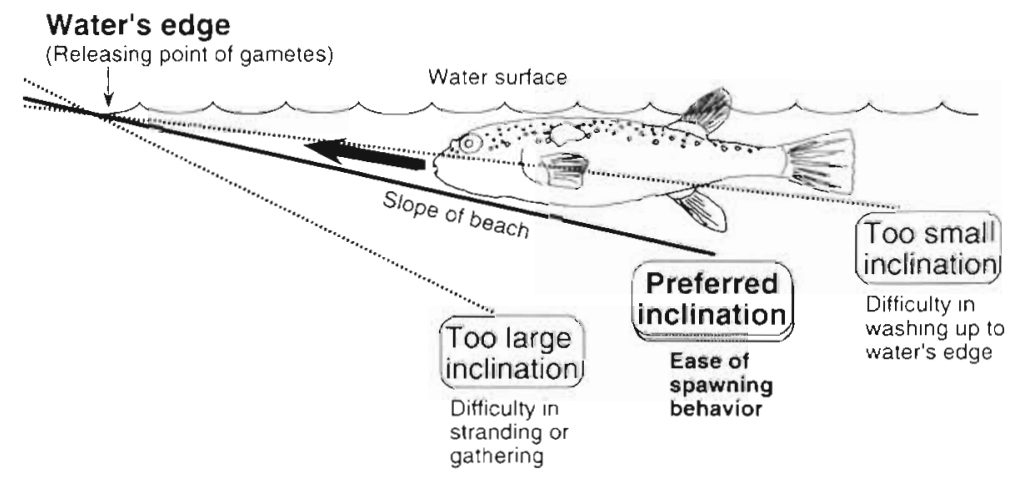

Fig. 5. Hypothesized relationship between inclination of a beach and spawning adult puffers (see text for details) 
Earlier studies have discussed ultimate factors that influence spawning site specificity of the puffer, and have paid special attention to factors that increase the survival of developing embryos. Katayama \& Fujita (1967) assumed that spawning sites of the puffer face south, and that such beaches can provide better conditions for embryonic development since they are warmer. However, in this study, spawning sites of the puffer were facing in various directions. Tsutsumi (1978) assumed that the puffer prefers beaches where underground water is oozing out, and that freshwater from underground has a favorable influence on the development of stranded eggs. However, my results show that underground water does not ooze out at all spawning sites.

Spawning site specificities have been reported for several other intertidal spawners. The mummichog Fundulus heteroclitus utilizes filamentous algae (Pearcy \& Richards 1962), empty shells of the Atlantic ribbed mussel Geukensia demissus (Able \& Castagna 1975), or primary leaves of cordgrass Spartina alterniflora as spawning substrates (Taylor et al. 1977, 1979). The Atlantic silverside Menidia menidia utilizes cordgrass, detrital mats, or abandoned crab burrows along eroding intertidal scarps (Middaugh et al. 1981). Spawning site specificity of these species also appears to be an advantage for embryo survival: each substrate provides protection from thermal stress as well as from predation (Middaugh et al. 1981).

In contrast, the present study has focused on the advantages of spawning sites for the adult spawners rather than for the developing embryos. Robertson (1991) has clearly distinguished the advantages for spawning adults (adult biology) from those for unhatched embryos or larvae (larval biology) to explain diel, lunar, and seasonal spawning cycles in marine fishes, and has emphasized the role of adult biology. The functions of spawning site specificity in many marine fishes have been explained by larval biology (survival, transport, or settlement of embryos and larvae; e.g. Johannes 1978, Lobel 1978, Middaugh et al. 1981). However, it might also reflect adult biology; that is, spawning fishes might use specific spawning sites because of, for example, ease of spawning, avoidance of predation, or simply as destinations for aggregation. To understand ultimate factors for the site-attached spawning of fishes, it seems to be important to take such adult biology into account.

Finally, this study indicates that examination of proximate factors can give us new models for the ultimate explanation. Such models might then allow testing by artificially altering various environmental features believed to be important. The identification of proximate factors also has an applied implication. For example, understanding the criteria used when selecting spawning sites would help to conserve existing spawning sites by ensuring that the selection criteria are maintained. In addition, such information might be used to create new spawning sites by artificial reconstruction of the environment.

Acknowledgements. I thank Prof. T. Kikuchi for giving me the opportunity to undertake this project. I also thank Dr Y Takada and the anonymous referees for making useful comments on the manuscript. Thanks are also due to Prof. $M$. Nozaki, T Minokawa, M. Aihara, M. Shimizu, Y Ishida, M. Taru, J. Takayama, and T Oyama for their helpful suggestions and field assistance. This study was supported by JSPS Fellowships for Junior Scientist (1150) and Grants-in-aid for Scientific Research from the Ministry of Education, Science, and Culture of Japan (1150). This is contribution No. 404 from the Amakusa Marine Biological Laboratory, Kyushu University.

\section{LITERATURE CITED}

Able KW, Castagna M (1975) Aspects of an undescribed reproductive behavior in Fundulus heteroclitus (Pisces: Cyprinodontidae) from Virginia. Chesapeake Sci 16:282-284

Colin PL, Clavijo IE (1978) Mass spawning of the spotted goatfish, Pseudupeneus maculatus (Pisces: Mullidae). Bull Mar Sci 28:780-782

Colin PL, Clavijo IE (1988) Spawning activity of fishes producing pelagic eggs on a shelf edge coral reef, southwestern Puerto Rico. Bull Mar Sci 43:249-279

Dotsu Y, Nakamura H, Nishikawa Y, Maeda I (1990) Spawning behavior of the grass puffer, Takifugu niphobles, in the vicinity of Nagasaki. Nagasakı-ken Seibutsu Gakkaishi 36:7-15 (in Japanese with English abstract)

Honma Y, Ozawa T, Chiba A (1980) Maturation and spawning behavior of the puffer, Fugu niphobles, occurring on the coast of Sado Island in the sea of Japan (a preliminary report). Japan J Ichthyol 27:129-138

Johannes RE (1978) Reproductive strategies of coastal marine fishes in the tropics. Environ Biol Fish 3:65-84

Katayama M, Fujita S (1966) Ecological studies on the puffer, Fugu niphobles (Jordan et Snyder) II. On the habit of burrowing into the bottom sand. Bull Fac Educ Yamaguchi Univ 13:35-44 (in Japanese with English synopsis)

Katayama M, Fujita S (1967) Ecological studies on the puffer Fugu niphobles (Jordan et Snyder) III. On the spawning beaches and spawning times in the Inland Sea side of Yamaguchi Prefecture. Buil Fac Educ Yamaguchi Univ 16 55-61 (in Japanese)

Katayama M, Fujita S. Fujioka Y (1964) Ecological studies on the puffer, Fugu niphobles (Jordan et Snyder) I. On the spawning habit. Bull Fac Educ Yamaguchi Univ 13:35-44 (in Japanese)

Komatsu T, Kawai H (1992) Measurements of time-averaged intensity of water motion with plaster balls. J Oceanogr 48 $353-365$

Lobel PS (1978) Diel, lunar, and seasonal periodicity in the reproductive behavior of the pomacanthid Centropyge potteri and some reef fishes in Hawaii. Pac Sci 32:193-207

Lobel PS, Robinson A (1983) Reef fishes at sea: ocean currents and the advection of larvae. Symp Ser Undersea Res. NOAA 1:29-38

Middaugh DP, Scott GI, Dean JM (1981) Reproductive behavior of the Atlantic silverside, Menidia menidia (Pisces: Atherinidae). Environ Biol Fish 6:269-276 
Miyamoto S (1982) Feeding ecology of the puffer, Fugu niphobles in the sand flat. Master (MSc) thesis, Kyushu Univ, Fukuoka

Nozaki $M$, Tsutsumi $T$, Kobayashi $H$, Takei $Y$, Ichikawa $T$, Tsuneki K, Miyagawa K, Uemura H, Tatsumi Y (1976) Spawning habit of the puffer, Fugu niphobles (Jordan et Snyder) I. Zool Mag (Tokyo) 85:156-168 (in Japanese with English abstract)

Pearcy WG, Richards SW (1962) Distribution and ecology of fishes of the Mystic River estuary, Connecticut. Ecology 43:248-259

Robertson DR (1991) The role of adult biology in the timing of spawning of tropical reef fishes. In: Sale PF (ed) The ecology of fishes on coral reefs. Academic Press, San Diego, p $356-386$

Suzuka M, Isogai S (1979) Spawning habit of the puffer, Fugu niphobles (Jordan et Snyder) at Koshigoe Beach of the Miura Peninsula. Sci Rep Yokosuka City Mus 24:57-66 (in Japanese with English abstract)

Taylor MH, DiMichele L, Leach GL (1977) Egg stranding in the life cycle of the mummichog. Fundulus heteroclitus. Copeia 1977:397-399

This article was presented by R. L. Haedrich (Senior Editorial Advisor), St. John's, Newfoundland, Canada
Taylor MH, Leach GL, DiMichele L, Levitan WM, Jacob WF (1979) Lunar spawning cycle in the mummichog, Fundulus heteroclitus (Pisces: Cyprinodontidae). Copeia 1979: 291-297

Thresher RE (1984) Reproduction in reef fishes. TFH Publications, Neptune City, NJ

Tsutsumi T (1978) Spawning habits of the blowfish, Fugu nuphobles. Heredity (Tokyo) 32:73-79 (in Japanese)

Uno Y (1955) Spawning habit and early development of a puffer, Fugu (Torafugu) niphobles (Jordan et Snyder). J Tokyo Univ Fish 42:169-183

Walker BW (1959) The timely grunion. Nat Hist 68 303-308

Warner RR (1988) Traditionality of mating-site preferences in a coral reef fish. Nature 355:719-721

Yamahira K (1994) Combined effects of tidal and diurnal cycles on spawning of the puffer, Takifugu niphobles (Tetraodontidae). Environ Biol Fish 40:255-261

Yamahira K, Nojima S, Kikuchi T (1996) Age specific food utilization and spatial distribution of the puffer, Takifugu niphobles, over an intertidal sand flat. Environ Biol Fish 45:311-318

Manuscript first received: September 28, 1995

Revised version accepted: December 11, 1996 